\title{
Energy Consumption Evaluation of AODV and AOMDV Routing Protocols in Mobile Ad-Hoc Networks
}

\author{
Fawaz Mahiuob Mohammed Mokbal \\ College of Computer Science \\ Beijing University of Technology \\ Beijing, China
}

\author{
Khalid Saeed \\ Department of Computer Science \\ Shaheed Benazir Bhutto University \\ Sheringal Dir Upper, Pakistan
}

\author{
Wang Dan \\ College of Computer Science \\ Beijing University of Technology \\ Beijing, China
}

\begin{abstract}
Mobile Ad-hoc Networks (MANETs) are mobile, multi-hop wireless networks that can be set up anytime, anywhere without the need of pre-existing infrastructure. Due to its dynamic topology the main challenge in such networks is to design dynamic routing protocols, which are efficient in terms of consumption of energy and producing less overhead. The main emphasis of this research is upon the prominent issues of MANETs such as energy efficiency and scalability along with some traditional performance metrics for performance evaluation. Two proactive routing protocols used in this research are single-path AODV versus multi-path AOMDV. Extensive simulation has been done in NS2 simulator, which includes ten scenarios. The simulation results revealed that the performance of AOMDV is more optimal as compared to AODV in terms of throughput, packet delivery fraction and end to end delay. However, in terms of consumption of energy and NRL the AODV protocol performed better as compared to AOMDV.
\end{abstract}

Keywords-MANETs; routing protocols; AODV; AOMDV; energy efficiency; routing performance

\section{INTRODUCTION}

In Mobile Ad-hoc Networks (MANETs) the mobile nodes can connect dynamically using a variety of wireless media without any centralized infrastructure [1]. There are many advantages of MANETs as compared to the traditional network such as ease of establishment of network, reduced infrastructure cost etc. In MANETs each mobile node not solely operates as a host but additionally works as a router and has the capability to perform routing [2]. The transmission range of the mobile nodes is limited due to which the nodes frequently join and leave the network and as a result, the network topology updates again and again [3]. The mobility of the nodes in MANETs can cause the links to break due to which the nodes recalculate routing information in order to establish the links. This process consumes power, processing time, memory and produces additional traffic [4]. The potential of the Ad-hoc networks is that it can be used in the situations where infrastructure is not available and technically not possible to deploy such as disaster and military operations. The situations can also include low power sensor networks [5].

In MANETs, routing is a very critical task that should be deal with very care. To send the data between the source node and the destination as well as to establish the connection, there is a need for routing protocols. Due to dynamic and unexpected topology changes in MANETs, the design of an efficient routing protocol in terms of consumption of energy and producing less overhead is very important and it is a significant challenge for such type of networks. The routing protocols have been developed to deal with the challenges, such as security, energy and delay. However, there are shortcomings in some aspects and improvement in others. Furthermore, the cooperative routing algorithms that are associated to energy gathering are quite limited [6].

There are few studies related to energy consumption calculation of wireless network in ad-hoc mode such as the research conducted in [7] proposed an energy efficient MAC protocol having multichannel and provisioning of quality of service in MANETs. The research conducted in [8] proposed an energy efficient secure selection of MPR mechanism which considers both security metrics as well as energy metrics for the selection of MPR. More specifically, there is a lack of detailed evaluation of energy consumption of mobile ad-hoc network protocols.

We believe that energy-aware designing and analysis of known-protocols for the ad-hoc networking environment needs sensible data of the energy consumption behavior of actual wireless nodes. Additionally, it's vital to present this information in a manner that is helpful to protocol developers as well as to researchers. The main focus of this research are benchmarking performance against criteria of energy efficiency and scalability along with most traditional performance metrics for performance evaluation of two proactive routing protocols. The first one is a single path named AODV [9, 10], while the second one is multi-path called AOMDV [11, 12] respectively. This research work provides a paradigm for future studies of the development of dynamic routing protocols which are more efficient in terms of energy consumption and producing less overhead. All of which are considered to be prominent issues of MANETs. This research utilized the mendeley reference manager [13] for organizing this research, as well as for referencing.

\section{A. MANETs Routing Protocols}

Generally, MANETs routing protocols are often categorized into the subsequent three categories [14, 15]: 
1) Proactive or Table-Driven routing protocols are based on the traditional link state and distance vector algorithms that are primarily meant for wired networks. These protocols maintained and periodically update their routing tables through interchanging the broadcast control messages.

2) Reactive or On-demand routing protocols are designed to have less overhead as compared to proactive routing protocols because the connection is only established when it is required by the source. This is typically done through a twostage process known as route discovery.

3) In order to increase the overall scalability of routing Hybrid routing protocols were introduced which includes the features of both reactive and proactive routing protocols. In hybrid routing protocols, the network is comprised of various zones. The network route within each zone is kept up proactively and the routes between zones are resolved responsively.

\section{B. Ad hoc On-Demand Distance Vector (AODV) Routing Protocol}

AODV $[9,10]$ is proactive, single path, loop-free distance vector routing protocol. It is based on DSR's on-demand route discovery mechanism, with the idea of destination sequence numbers from DSDV, but it is different from DSDV by using hop-by-hop routing approach. AODV maintains routes only between nodes which need to communicate with each other. Each mobile node keeps a routing table which maintains information about next-hop of a path towards the destination node. In order to transport packets correctly towards the destination, the protocol uses two procedures: Route discovery of route between the source and the destination and route maintenance. It uses route request message (RREQ) and route reply message (RREP) for route discovery, and uses Route Error (RERR) for route maintenance. Moreover, Hello messages are used to preserve the connectivity between neighboring nodes.

\section{Ad hoc On-Demand Multipath Distance Vector Routing Protocol}

Depending upon the distance vector idea and utilizing hopto-hop routing concept AOMDV discover routes on-demand utilizing a route discovery technique. The primary difference between AOMDV and AODV lies within the number of routes found in every route discovery [11]. The essence of the AOMDV protocol lies on guaranteeing that multiple paths discovered will be loop-free as well as disjoint, and in effectively finding such routes utilizing a flood-based route discovery [12]. Route update runs in AOMDV are executed locally at each node which has a key part in keeping up loopfreedom and disjoint attributes.

The rest of the paper is organized as follows: Section II includes the relevant research work done. Section III contains the research methodology adopted for carrying out this research. In Section IV results generated are discussed in detail. In Section V the research work done is concluded and at the end there are references.

\section{LITERATURE REVIEW}

Although energy consumption is agreed to be of importance within the design of ad-hoc networks routing protocols. However, most of studies regarding performance evaluation relied on traditional performance parameters such as throughput, end-to-end delay, PDF and NRL. Moreover, there is a great need to investigate the energy consumption of known protocols in MANETs for future researches.

The research that has been done in MANETs follows two trends, The first trend is the research work related to the design of efficient ad-hoc routing protocols aiming to achieve one or a combination of the targets such as increase in the packet delivery, minimizing energy consumption, and reducing the overheads in MANETs [16]-[24]. However, there are shortcomings in some aspects and improvement in others. The second, upon which the vast majority of research focuses, is performance evaluation based on traditional performance metrics [25]-[31].

The research conducted in [16] proposed a novel faulttolerant routing approach utilizing a stochastic learning-based weak estimation procedure. The proposed scheme aims to make routing protocol successfully operate in adversarial environment. Authors in [17] have tried to reduce the waste of the limited battery power that occur in exchanging cluster maintenance messages by assigning critical node that has highest priority to be selected as a cluster head, as a results, limited battery power is preserved.

The research conducted in [18] proposed a dynamic energy efficiency algorithm which aims to extend the network lifespan, the proposed approach used two threshold ,yellow threshold that was used to obtain some sort of local load balancing via distributing the load equally among the neighboring cluster-heads, and a red thresholds that was used to prompt local re-clustering in the network. The result obtained in this research revealed that the proposed approach achieved better efficiency than those found in existing weight clustering approach.

The research conducted in [19] proposed a Bird FlightInspired Routing Protocol (BFIRP), the aim was to make highly scalable, dynamic, energy efficient, and position-based routing protocol. The proposal was based on three-dimensional $(\mathrm{X}, \mathrm{Y}, \mathrm{Z})$ to determine the source and destination location. The outcomes demonstrate that the algorithm was highly scalable, and had low end-to-end delay compared to AODV as well as more efficient than AODV in terms of energy and throughput by $20 \%$ and $15 \%$ respectively.

The research conducted in [20] proposed learning automata based fault-tolerant routing algorithm which is able to perform routing in the existence of faulty nodes in MANETs. To achieve the optimize selection of paths, decrease the overhead in the network, and for learning about the faulty nodes existence in the network, they have utilized the theory of Learning Automata. The outcomes demonstrate that the packet delivery ratio increased and the overhead decreased as compared to the AODV protocol.

The research conducted in [21] proposed energy efficiency algorithm for a communication network in MANETs. The 
proposal aims to optimize energy consumption through selecting the best path in terms of energy for transferring data after computing the energy required for each available path.

The research conducted in [22] proposed Ant-Colony Optimization (ACO) approach for selecting the optimal cluster heads. The aim was optimization of energy consumption as well as stability of the node. The probability function was used to compute the parameters like residual energy, energy drain rate and mobility factor. Node that has the highest value for the probability function will be selected as a cluster-head. The overall workload of communication is computed periodically. The cluster head is reset, if its value is high. The outcome shows that the approach has energy efficiency and clusters stability.

The research conducted in [23] attempted to decrease energy consumption and delay in MANETs. The proposed approach computed the important matrices such as Residual Energy, Node connectivity and Available Bandwidth for election of the cluster head efficiently. A conscious cluster routing algorithm was proposed by using constructed shortest path multicast tree that pick a cluster head as group leader and cluster members as leaf nodes. The most proposed approaches are extension of some of the current protocols which are either reactive protocols such as AODV and DSR or proactive protocols such as OLSR and DSDV.

The research conducted in [24] proposed the AOMDV-ER for improving of network lifetime and reduce routing overhead by using recoil off time technique based on their geographical location in order to reduce the number of transmissions. The outcomes show that the proposed scheme such as AOMDV-ER was able to save energy consumption up to $16 \%$, and $12 \%$ reduction in routing overhead.

The second working trend are research on benchmarking and performance analysis of known network protocols, focused on traditional performance metrics such as PDF, throughput and End-to-End delay; or survey studies.

AODV and AOMDV in [25], [26] are compared with connections up to 50. They have concluded that AOMDV has more routing overhead and delay as compared to AODV, but it has better efficiency in packet drop and PDF.

The research conducted in [27] evaluated the performance of DSR, AODV and AOMDV routing protocol in MANETs by comparing the PDR, throughput, and end-to-end delay. They observed that in a network with increased number of nodes up to 20 nodes, PDF and throughput in AOMDV and DSR routing protocols are better as compared to AODV whereas the delay is less in AOMDV as compared to DSR and AODV.

The survey conducted in [28] reviewed typical reactive routing protocols and revealed the characteristics and trade-offs of AODV, AODV-UU, AOMDV, DSR and DYMO. They have concluded that each of the protocol in the conducted research performs well in some cases and has certain drawbacks in others scenarios.

The performance of AODV, AOMDV, DSR and DSDV were evaluated in [29] through comparing the PDR, packet loss ratio, and end-to-end delay performance matrices for wireless networks. They observed that the performance of AODV is best as compared to AOMDV, DSDV and DSR and therefore the performance of DSR is best as compared to AODV, AOMDV and DSDV in TCP connection type as well as in CBR connection type.

The research conducted in [30] compared and analyzed the performance of AODV and AOMDV routing protocols in MANETs relying on the traditional performance metrics like throughput, end-to-end delay, PDF. They have observed that AOMDV performs well as compared to AODV in terms of PDF and throughput, however, AOMDV incurs a lot of delay in comparison to AODV.

The research conducted in [31] includes AODV, AOMDV, DSDV and DSR. They examined the effect of dynamic change in network topology on the performance based on traditional metrics such as PDR, end-to-end delay and NRL. They observed that AOMDV and DSDV are not suitable when the network topology updates again and again, while AODV and DSR are suitable in such scenario. DSR and DSDV performed better as compared to other protocols in terms of packet delivery ratio, end-to-end delay and NRL. AOMDV had less end-to-end delay but when the network topology changes more frequently, the PDF and NRL are worst as compared to other protocols.

\section{RESEARCH METHODOLOGY}

This research is based on evaluating the performance of AODV and AOMDV routing protocols in varied aspects, especially in energy consumption. To evaluate the performance, these protocols are simulated using NS-2 version 35 (The Network Simulator - ns-2, https://www.isi.edu/nsnam/ns) [32]. The simulation workflow is shown in Fig. 1.

\section{A. Simulation Environment}

NS2.35 is an object oriented simulator, which is built by combining the advantages of $\mathrm{C}++$ with an OTcl languages. NS2 has full supports for multi-hop wireless ad-hoc environment integrated with physical, data link, and medium access control (MAC) layer model [33]. This research utilized these advantages of NS simulator to set and configure the environment for this research. The protocols have a send buffer of 64 packets to maintain the data packets start with route discovery phase, which are waiting to get the route that has not yet arrived. The mechanism that prevents unlimited buffering is to drop packets in buffer that took longer than 30 seconds. The interface queue that has a maximum size of 50 packets is used to maintain the routing layer packets that are sent until the MAC layer transmits them. The interface queue has two priorities for packets, each perform FIFO order mechanism. The higher primacy is given to routing packets as opposed to data packets [34].

The evaluations in this research depends on the simulation of 10, 20, 30, 40 and 50 wireless nodes for each protocol, moving randomly along a simulation area $(800 \mathrm{~m} \times 800 \mathrm{~m})$ flat grid for 100 seconds simulation time. A square field grants nodes to move freely with a similar density. For the sake of a fair comparison between the two protocols, we have made the same environment and the same parameters for both protocols mentioned in Table I. Fig. 2 shows the simulation environment setup and configuration. 


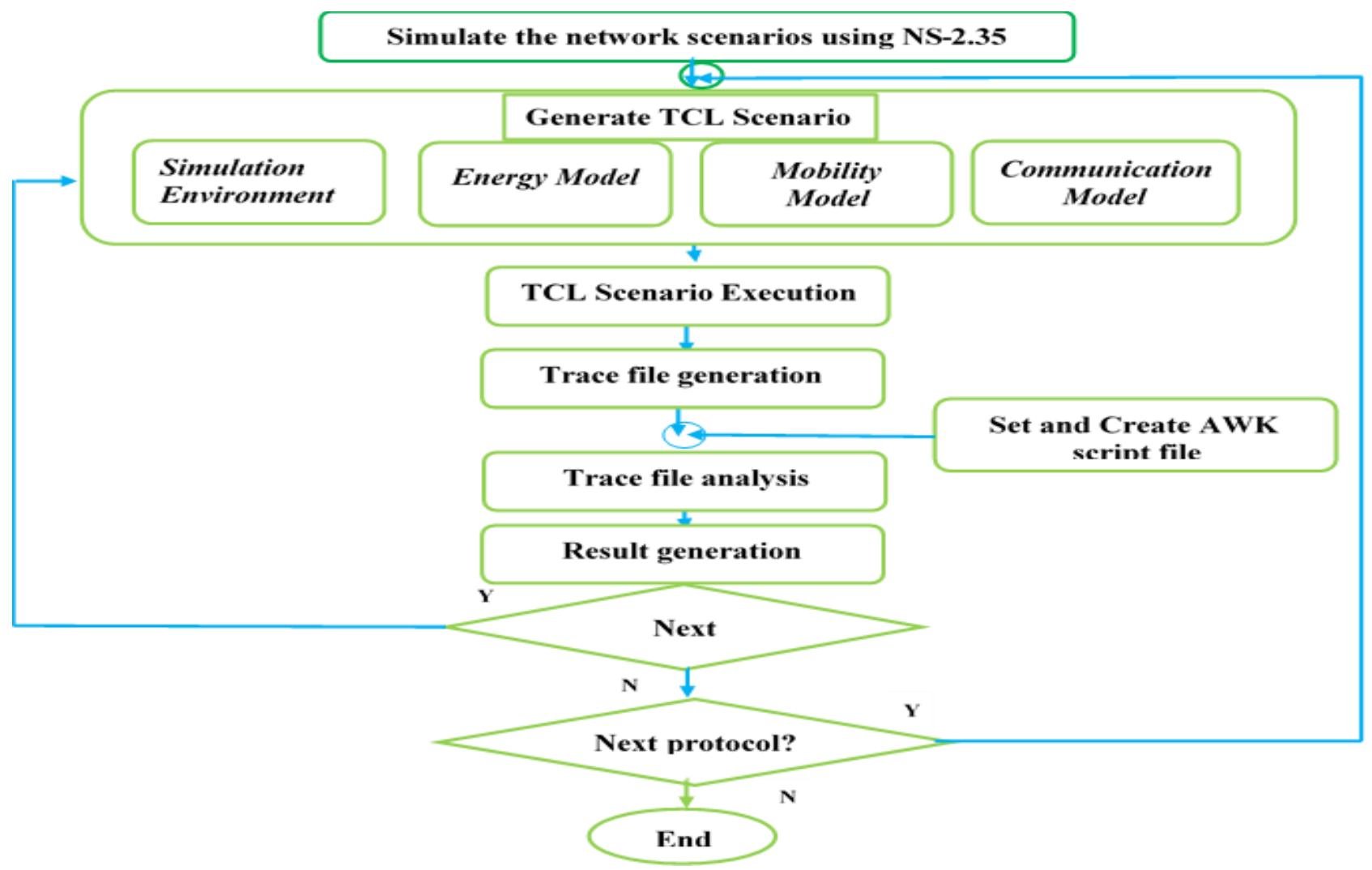

Fig. 1. Simulation Workflow.

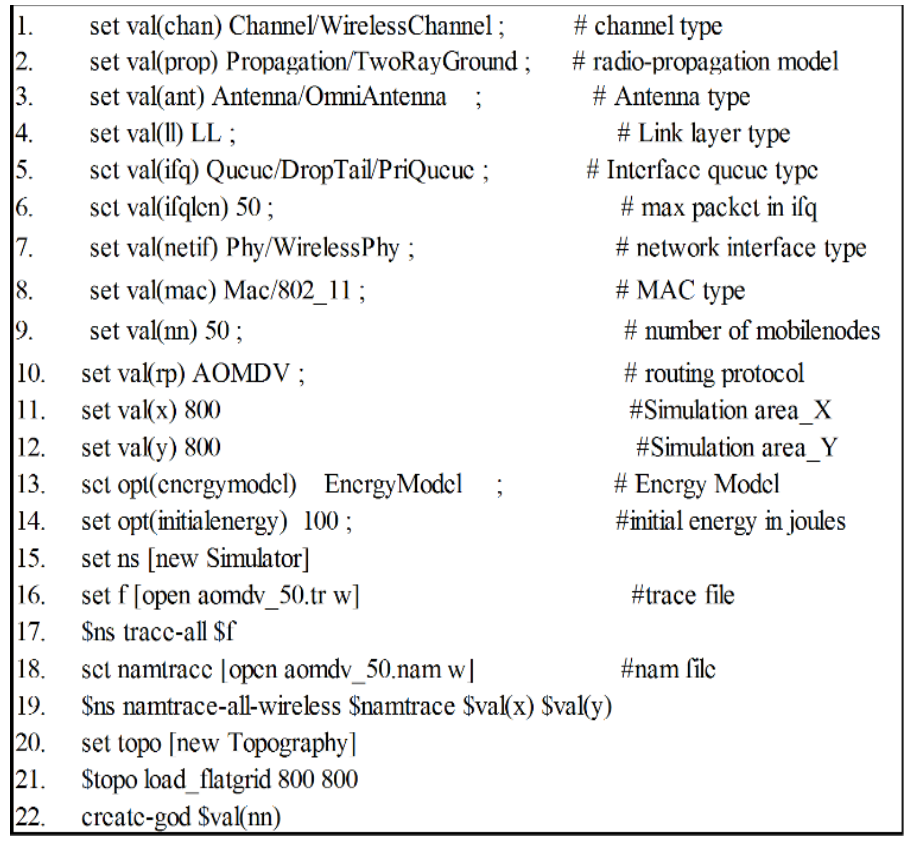

Fig. 2. Simulation Environment Configuration.

\section{B. Energy Model}

The parameters of energy model used in this research are mentioned in Table I and its detail is reflected in Fig. 3. The energy model is used to measure the power consumed in each scenario. The node consumes the available energy (initial energy) based on the following parameters: (1) Transmission
(Tx) (2) Reception (Rx) (3) Idle (4) Sleep (5) TransitionPower and (6) TransitionTime states. Transmission manner indicates the energy consumed (Watt) for transferring each packet, reception manner indicates the energy consumed (Watt) for receiving each packet, idle manner indicates the energy consumed (Watt) when the node is in idle mode, sleep manner indicates the energy consumed (Watt) when the node is in sleep mode, TransitionPower indicates the energy consumed (Watt) in case of transition from sleep to idle. TransitionTime indicates the time (second) which is used in case of transition from sleep to idle.

TABLE I. SimUlation PaRAMETERS

\begin{tabular}{|l|l|l|l|}
\hline Parameter & Value & Parameter & Value \\
\hline $\begin{array}{l}\text { Network } \\
\text { Simulator }\end{array}$ & NS2.35 & $\begin{array}{l}\text { Transition } \\
\text { Power }\end{array}$ & $0.2 \mathrm{~W}$ \\
\hline Type of Channel & Wireless Channel & $\begin{array}{l}\text { Transition } \\
\text { Time }\end{array}$ & $0.005 \mathrm{~S}$ \\
\hline $\begin{array}{l}\text { Radio } \\
\text { Propagation } \\
\text { Model }\end{array}$ & Two Ray Ground & $\begin{array}{l}\text { Routing } \\
\text { Protocols }\end{array}$ & $\begin{array}{l}\text { AODV, } \\
\text { AOMDV }\end{array}$ \\
\hline Type of Antenna & Omni Antenna & $\begin{array}{l}\text { Mobility } \\
\text { Model }\end{array}$ & $\begin{array}{l}\text { Random } \\
\text { Waypoint }\end{array}$ \\
\hline $\begin{array}{l}\text { Type of Interface } \\
\text { queue }\end{array}$ & DropTail/PriQueue & $\begin{array}{l}\text { Simulation } \\
\text { Time }\end{array}$ & 100 seconds \\
\hline $\begin{array}{l}\text { Max Packet in } \\
\text { Ifqueue }\end{array}$ & 50 & $\begin{array}{l}\text { Number of } \\
\text { Scenarios }\end{array}$ & $10(5 \times 2)$ \\
\hline $\begin{array}{l}\text { Type of Network } \\
\text { Interface }\end{array}$ & Phy/WirelessPhy & $\begin{array}{l}\text { Number of } \\
\text { Nodes }\end{array}$ & $10,20,30,40,50$ \\
\hline
\end{tabular}




\begin{tabular}{|l|l|l|l|}
\hline $\begin{array}{l}\text { Type of MAC } \\
\text { layer }\end{array}$ & Mac/802.11 & $\begin{array}{l}\text { Transport } \\
\text { Layer } \\
\text { Protocol }\end{array}$ & $\begin{array}{l}\text { UDP (User } \\
\text { Datagram } \\
\text { Protocol) }\end{array}$ \\
\hline Simulation Area & $800 \mathrm{~m} \times 800 \mathrm{~m}$ & $\begin{array}{l}\text { Traffic } \\
\text { Model }\end{array}$ & $\begin{array}{l}\text { CBR (Constant } \\
\text { Bit Rate) }\end{array}$ \\
\hline $\begin{array}{l}\text { Initial Energy for } \\
\text { Each Node }\end{array}$ & 100 Joule & Packet Size & 512 bytes \\
\hline $\begin{array}{l}\text { Transmission } \\
\text { Power }\end{array}$ & $2.0 \mathrm{~W}$ & $\begin{array}{l}\text { Link } \\
\text { Capacity }\end{array}$ & 1.0 Mbps \\
\hline Reception Power & $1.0 \mathrm{~W}$ & $\begin{array}{l}\text { Connection } \\
\text { Rate }\end{array}$ & 4 packets $/ \mathrm{sec}$ \\
\hline Idle Power & $0.5 \mathrm{~W}$ & $\begin{array}{l}\text { Number of } \\
\text { Connections }\end{array}$ & $1,2,3,4,5$ \\
\hline Sleep Power & $0.001 \mathrm{~W}$ & Node Speed & $10 \mathrm{~m} / \mathrm{s}$ \\
\hline
\end{tabular}

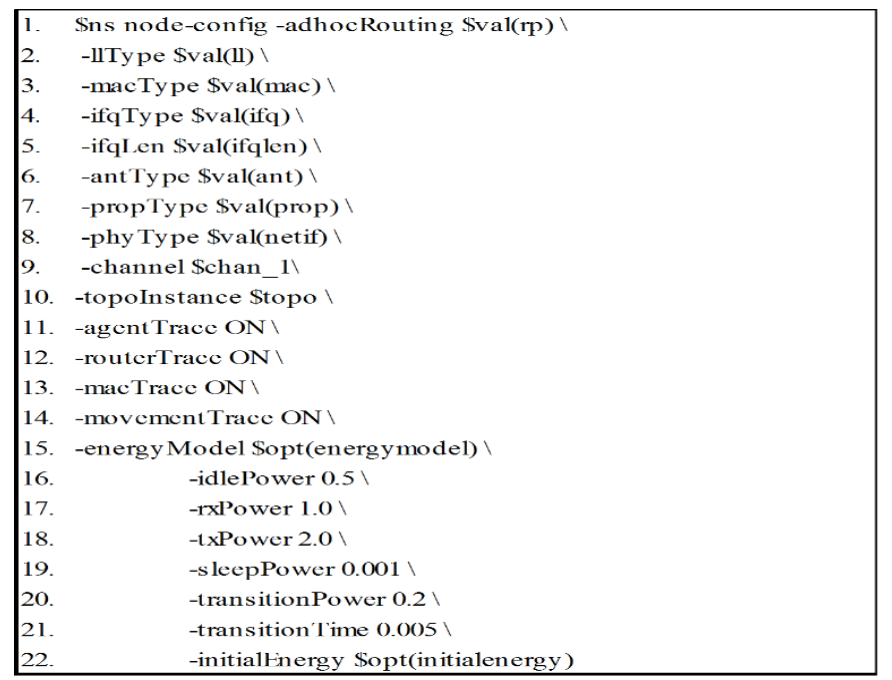

Fig. 3. Energy Model.

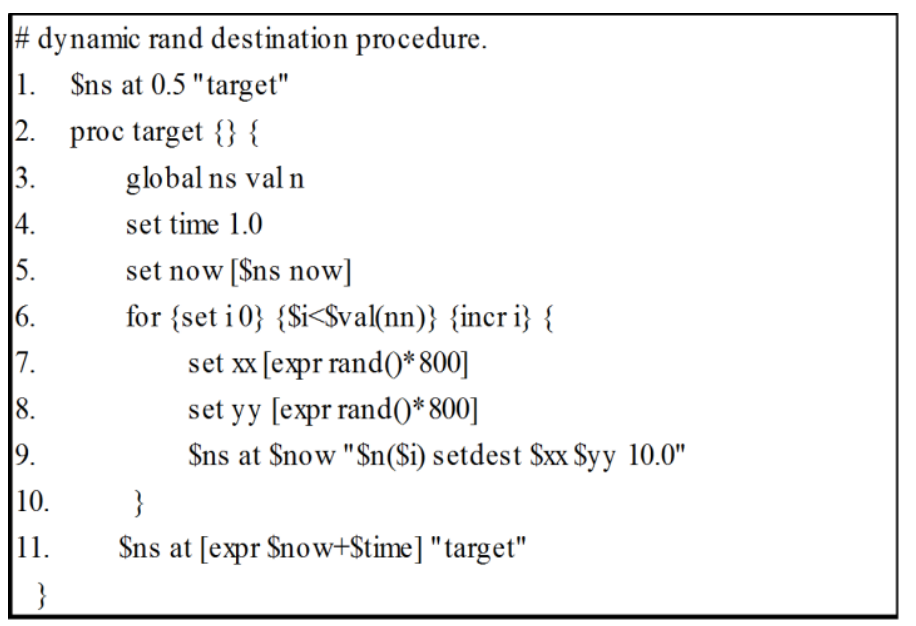

Fig. 4. Dynamic Mobility Function.

\section{Mobility Model}

In this research, the mobility model used is random waypoint, in which the mobile node move randomly and update their location, speed and acceleration change over time. It is simple and widely available model, thus, it is the most common mobility models to evaluate MANETs routing protocol [35]. In this research, node movement is done by dynamic destination setting procedure as shown in Fig. 4. The scenario files utilized for each simulation are distinguished by same pause time which is $0.5 \mathrm{~s}$. All nodes start the simulation by remaining stationary for the pause time period. At the end of pause time period, the node randomly select destination in the simulation area, moving in space at a uniform speed of $10 \mathrm{~m} / \mathrm{s}$ for the entire period of the simulation.

\section{Communication Model}

This research used the traffic pattern to be constant bit rate (CBR) source over the User Datagram Protocol (UDP) at transport layer. The origin and target pairs are spread randomly across the network. Packets size 512 bytes is used, while the number of CBR packets generated vary based on the connection rate, Hence, for all scenarios in these simulations, we choose to fix connection rate at 4 packets/sec. Five different communication patterns corresponding to $1,2,3,4$ and 5 connections for $10,20,30,40,50$ nodes respectively were considered. The communication pattern of 5 connections is shown in Fig. 5.

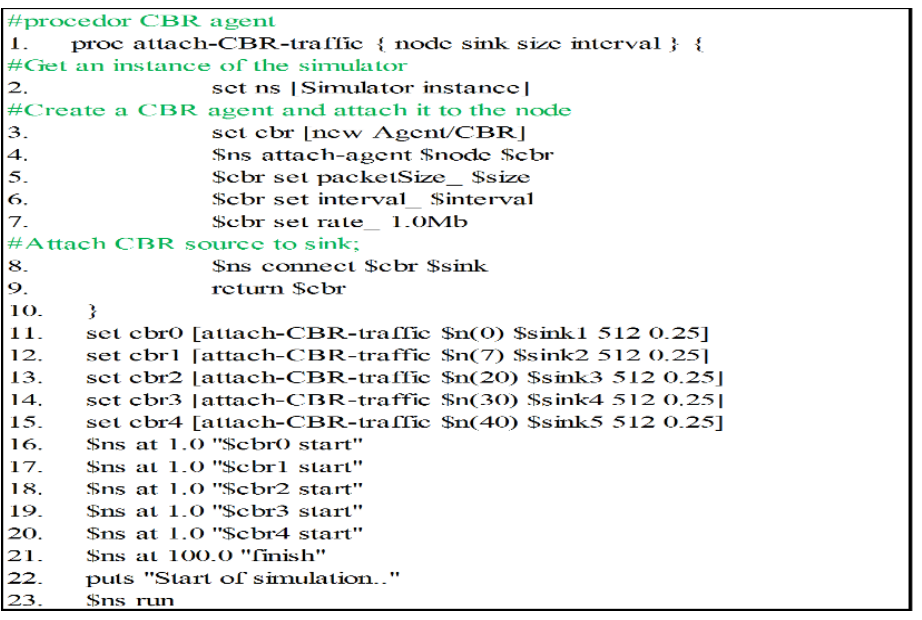

Fig. 5. Communication Pattern.

\section{E. Performance Metrics Used in Simulation}

In order to evaluate the performance of AODV and AOMDV, we considered the eight most commonly used quantitative indicators to judge the performance of the protocols: (1) Total Energy consumed by all nodes (TE); (2) Average Consumed Energy (ACE); (3) Average Residual Energy (ARE); (4) Packet Delivery Fraction (PDF); (5) Throughput Rate [kbps]; (6) End-to-End delay (E2ED); (7) Routing Load and (8) Normalized Routing Load.

1) Total Energy consumed by all nodes (TE): Energy consumption is computed as follows:

The time needed for transmitting a data packet is

Time $=8 \times($ Psize $/ B W)$

Therefore, we have:

$$
\begin{aligned}
& E t i=\text { Pti } \times \text { Time } \\
& \text { Eri }=\text { Pri } \times \text { Time } . \\
& \text { EId } i=\text { PId } \quad \times \text { Time }
\end{aligned}
$$


The transition power mode with transition time $(t t)$ is as follows: Etpi $=$ Ptpi $\times$ Time $(t t)$

Where Eti indicates the amount of energy consumed by a node $i$ in the transmission power mode, Eri indicate the amount of energy consumed by a node $i$ in the Reception Power mode, EId indicates the amount of energy consumed by a node $i$ in the Idle mode, Esi indicates the amount of energy consumed by a node $i$ in the sleeping mode, and Etpi indicates the amount of energy consumed by a node $i$ in the TransitionPower mode with TransitionTime $(t t)$ which is used for transition from sleep to idle. The total energy consumed by a node $i$ is calculated as:

TotalE $i=E t i+E r i+E I d i+E I d i+E s i+E t$

The Total Energy consumed (TE) by all nodes $(\mathrm{N})$ is:

$T E=\sum_{i=0}^{N}$ TotalE $i$

2) Average Consumed Energy ( $A C E)$ : It refers to the ratio of total energy consumed by each nodes (TE) to the number of nodes $(\mathrm{N})$.

$A C E=\frac{T E}{N}$

3) Average Residual Energy ( $A R E)$ : It refers to the ratio of total initial energy of all nodes (IE) - total energy consumed by all nodes (TE) divided by number of nodes $\mathrm{N}$.

$A R E=\frac{\sum_{i=0}^{N} I E-\sum_{i=0}^{N} T E}{N}$

4) Packet Delivery Fraction (PDF): It indicates the ratio of correctly received packets to all sent packets in a period. It is an appraisal indicator of the reliability of transmission in AdHoc network. The smaller value the packet delivery shows the worst performance.

$\left.P D F=\sum_{i=0}^{N} \operatorname{Pr} i\right) /\left(\sum_{i=0}^{N} P s i\right)$

$\mathrm{N}$ is the total number of nodes, Pri is the number of packets received by node $i$, Psi is the number of packets sent by node $i$.

5) Throughput Rate [kbps] (TR): It points to the total received packets' size successfully reached at target per unit time.

$T R[$ kbps $]=\frac{\text { recevd }_{\text {size }}}{\text { Stop }_{T}-\text { Start }_{T}} \times \frac{8}{1000}$

6) End-to-End Delay (E2ED): The time taken by the data packets to be arrived at destination sent by the source is known as Average End-to-End Delay. The Average End-to-End delay value refers to the time used for all potential delays results in buffering procedure, interface queuing, the retransmission procedure executed at MAC and propagation times. The lower the delay time, the better the efficiency.

Average $E 2 E D=\frac{1}{N P} \sum_{i=0}^{N P}(R t(i)-S t(i))$

Where NP refers to total number of the packets received successfully, Rti points to the time when the packet $i$ is received, Sti points to the time when the packet was sent.
7) Routing Load: The total routing packets transmitted including the packets which are forwarded at network layer are known as Routing Load.

Routing Laod $=$ CPSn + CPFn

where, CPSn points to the number of routing control packets generated to be sent, CPFn points to the number of routing control packets to be forwarded, CPSn and COFn at network layer.

8) Normalized Routing Load (NRL): Normalized routing load is the average number of routing control packets transmitted at network layer per data packets received by destination at the application layer. It refers to the congestion status of the network. The higher routing load increases the probability of network congestion.

$N R L=\frac{\text { Routing Laod }}{D P n}$

Where DPn refers the total number of the data packets received.

\section{RESUlTS AND DisCUSSION}

This section includes the details discussion about the results generated during simulation. In this research for analyzing the trace file for each scenario the AWK scripting language [36], [37] is used. Fig. 6 illustrates the energy tracking function of nodes which uses the trace files generated through simulation as input and store the output in the matrix. While Fig. 7 illustrates compute function of energy that is consumed by nodes, which uses the output of tracking function as input and compute consumed energy for each node as output.

Tables II, III, IV, V and VI show the results obtained regarding energy consumption by each node in the various scenarios separately for both protocols AODV and AOMDV.

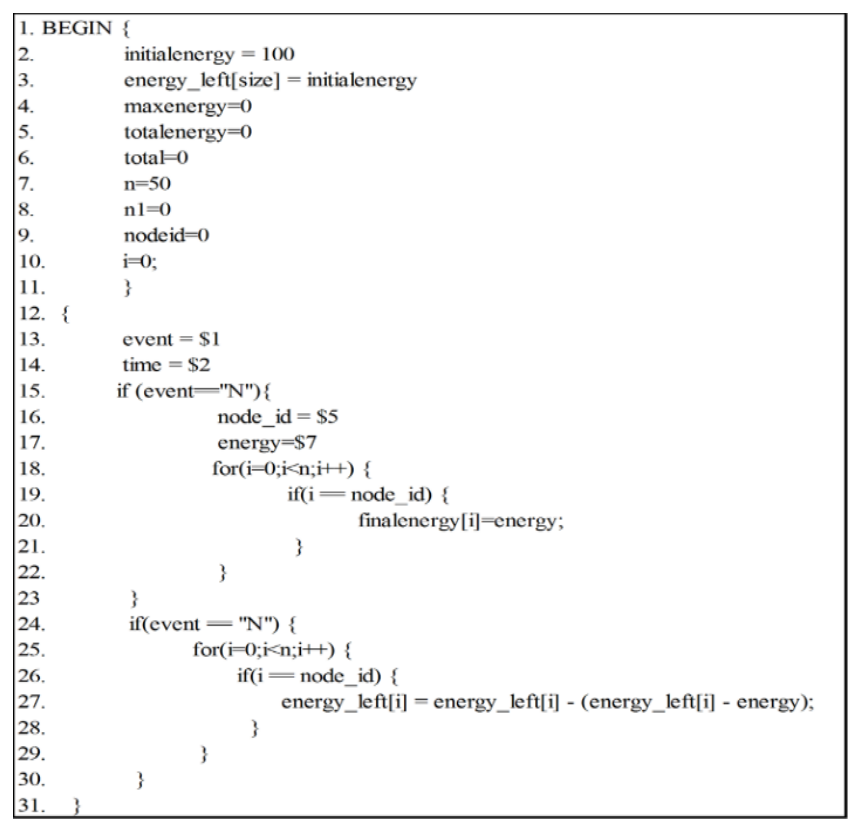

Fig. 6. Energy Tracking Function. 


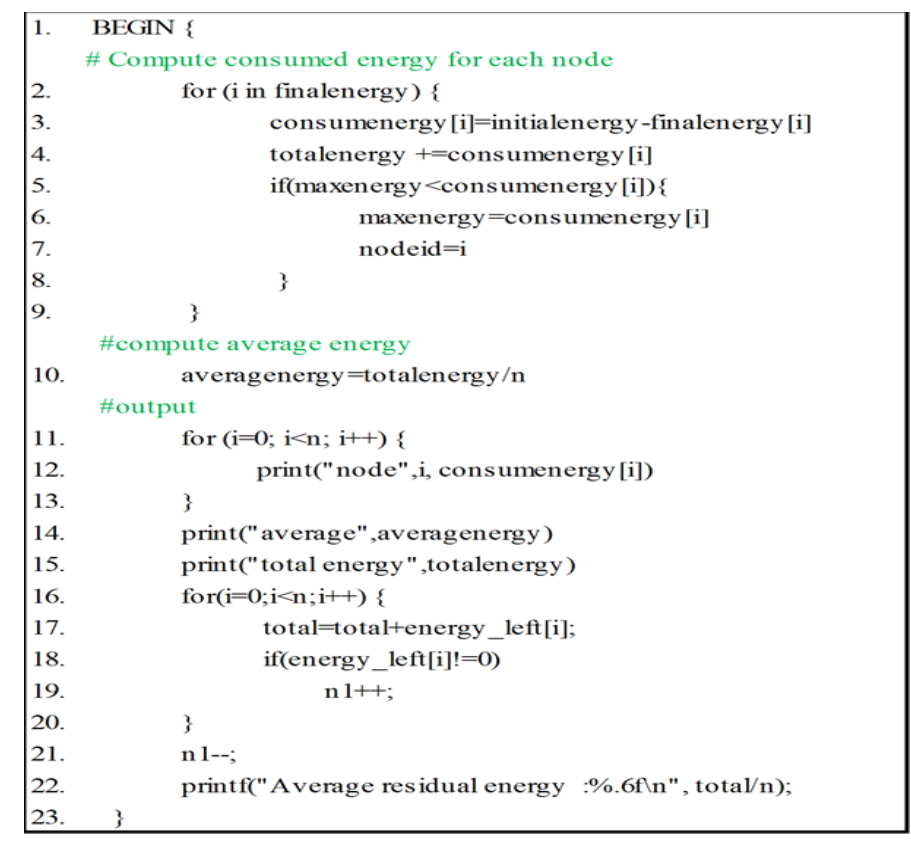

Fig. 7. Compute Consumed Energy Function.

TABLE II. ENERGY CONSUMPTION BY EACH NODE IN 10 NODES SCENARIO

\begin{tabular}{|l|l|l|l|l|l|}
\hline Node No. & AODV & AOMDV & $\begin{array}{l}\text { Node } \\
\text { No. }\end{array}$ & AODV & AOMDV \\
\hline 0 & 55.2753 & 55.8414 & 5 & 55.5218 & 56.0896 \\
\hline 1 & 53.4916 & 54.0586 & 6 & 53.2687 & 53.8353 \\
\hline 2 & 53.2687 & 53.8403 & 7 & 53.2143 & 53.7748 \\
\hline 3 & 55.5221 & 56.0913 & 8 & 53.2687 & 53.8362 \\
\hline 4 & 53.2687 & 53.7633 & 9 & 53.2687 & 53.8386 \\
\hline
\end{tabular}

TABLE III. ENERGY CONSUMPTION BY EACH NODE IN 20 NODES SCENARIO

\begin{tabular}{|l|l|l|l|l|l|}
\hline Node No. & AODV & AOMDV & $\begin{array}{l}\text { Node } \\
\text { No. }\end{array}$ & AODV & AOMDV \\
\hline 0 & 59.7815 & 59.6455 & 10 & 57.8163 & 57.7453 \\
\hline 1 & 58.0402 & 57.9685 & 11 & 57.8163 & 57.7374 \\
\hline 2 & 58.0594 & 57.9863 & 12 & 57.8163 & 57.7341 \\
\hline 3 & 57.8163 & 57.7386 & 13 & 57.6738 & 57.6145 \\
\hline 4 & 60.0735 & 57.7366 & 14 & 60.0701 & 57.7366 \\
\hline 5 & 57.8163 & 57.7341 & 15 & 57.8163 & 59.9957 \\
\hline 6 & 60.0697 & 57.7332 & 16 & 60.0704 & 57.7378 \\
\hline 7 & 59.8023 & 59.7733 & 17 & 57.8163 & 57.7357 \\
\hline 8 & 57.8163 & 59.9987 & 18 & 60.0613 & 59.9865 \\
\hline 9 & 57.8163 & 60.0051 & 19 & 57.8163 & 57.7378 \\
\hline
\end{tabular}

TABLE IV. ENERGy CONSUMPTION BY EACH NODE IN 30 NODES SCENARIO

\begin{tabular}{|l|l|l|l|l|l|}
\hline Node No. & AODV & AOMDV & $\begin{array}{l}\text { Node } \\
\text { No. }\end{array}$ & AODV & AOMDV \\
\hline 0 & 62.0289 & 62.3113 & 15 & 62.3425 & 60.4472 \\
\hline 1 & 62.4216 & 60.6681 & 16 & 60.0786 & 62.7112 \\
\hline 2 & 60.3226 & 60.6946 & 17 & 60.0786 & 60.4405 \\
\hline 3 & 60.0786 & 62.71 & 18 & 62.3304 & 60.4111 \\
\hline 4 & 60.2165 & 60.4458 & 19 & 60.0786 & 60.442 \\
\hline 5 & 60.0786 & 60.4421 & 20 & 62.1021 & 62.4772 \\
\hline 6 & 60.078 & 60.3897 & 21 & 60.3209 & 60.7035 \\
\hline 7 & 62.0824 & 62.3957 & 22 & 60.0786 & 60.4405 \\
\hline 8 & 60.0786 & 60.4496 & 23 & 60.0786 & 60.4428 \\
\hline 9 & 62.2012 & 60.4561 & 24 & 60.0786 & 60.4429 \\
\hline 10 & 60.0786 & 60.4412 & 25 & 60.0786 & 60.4491 \\
\hline 11 & 62.3355 & 60.4604 & 26 & 62.3341 & 62.7078 \\
\hline 12 & 60.0786 & 60.4413 & 27 & 60.0786 & 60.4471 \\
\hline 13 & 59.975 & 62.686 & 28 & 59.9649 & 60.2529 \\
\hline 14 & 60.0786 & 62.7056 & 29 & 60.0265 & 60.3115 \\
\hline
\end{tabular}

TABLE V. ENERGY CONSUMPTION BY EACH NODE IN 40 NODES SCENARIO

\begin{tabular}{|l|l|l|l|l|l|}
\hline Node No. & AODV & AOMDV & $\begin{array}{l}\text { Node } \\
\text { No. }\end{array}$ & AODV & AOMDV \\
\hline 0 & 68.8375 & 68.2596 & 20 & 68.9956 & 68.4826 \\
\hline 1 & 71.4571 & 66.6842 & 21 & 67.2109 & 66.6952 \\
\hline 2 & 69.331 & 66.7028 & 22 & 66.9651 & 66.4381 \\
\hline 3 & 69.0919 & 66.452 & 23 & 66.9685 & 66.4482 \\
\hline 4 & 69.3759 & 66.4544 & 24 & 71.4909 & 66.4494 \\
\hline 5 & 67.1073 & 66.4397 & 25 & 66.9685 & 66.4499 \\
\hline 6 & 66.9337 & 68.6657 & 26 & 69.242 & 66.4486 \\
\hline 7 & 68.8342 & 68.4365 & 27 & 66.9679 & 66.4493 \\
\hline 8 & 66.9685 & 68.7176 & 28 & 69.085 & 66.1894 \\
\hline 9 & 66.9685 & 68.7181 & 29 & 66.862 & 66.3122 \\
\hline 10 & 66.9685 & 68.7128 & 30 & 68.8081 & 68.3569 \\
\hline 11 & 66.9685 & 70.9735 & 31 & 67.0836 & 66.5254 \\
\hline 12 & 69.2285 & 66.4527 & 32 & 66.9685 & 66.4462 \\
\hline 13 & 66.7829 & 68.6642 & 33 & 66.9658 & 66.4346 \\
\hline 14 & 66.9685 & 66.4478 & 34 & 66.9685 & 66.4486 \\
\hline 15 & 66.9685 & 66.4478 & 35 & 66.9685 & 66.4487 \\
\hline 16 & 69.2305 & 68.717 & 36 & 66.9563 & 66.4145 \\
\hline 17 & 66.9679 & 66.4428 & 37 & 66.6084 & 66.2002 \\
\hline 18 & 66.9229 & 66.328 & 38 & 66.9018 & 66.3646 \\
\hline 19 & 67.1089 & 66.4519 & 39 & 66.9685 & 68.7203 \\
\hline
\end{tabular}


TABLE VI. ENERGY CONSUMPTION BY EACH NODE IN 50 NODES SCENARIO

\begin{tabular}{|l|l|l|l|l|l|}
\hline Node No. & AODV & AOMDV & $\begin{array}{l}\text { Node } \\
\text { No. }\end{array}$ & AODV & AOMDV \\
\hline 0 & 66.7606 & 73.3017 & 25 & 64.8803 & 73.8995 \\
\hline 1 & 65.1066 & 71.875 & 26 & 64.8799 & 71.6341 \\
\hline 2 & 67.2366 & 71.8762 & 27 & 67.1378 & 73.8461 \\
\hline 3 & 64.973 & 71.6389 & 28 & 64.6579 & 71.2808 \\
\hline 4 & 67.1531 & 71.6319 & 29 & 64.7657 & 71.3901 \\
\hline 5 & 64.967 & 71.5672 & 30 & 66.7479 & 73.4913 \\
\hline 6 & 64.8442 & 71.5385 & 31 & 65.0551 & 71.5351 \\
\hline 7 & 66.8665 & 73.613 & 32 & 64.883 & 71.6359 \\
\hline 8 & 64.8819 & 71.6327 & 33 & 64.8614 & 71.6213 \\
\hline 9 & 67.1568 & 71.6373 & 34 & 64.8771 & 71.6133 \\
\hline 10 & 67.1546 & 72.5123 & 35 & 64.8786 & 71.6206 \\
\hline 11 & 64.882 & 71.6337 & 36 & 64.7843 & 73.8235 \\
\hline 12 & 64.9353 & 71.6114 & 37 & 64.534 & 73.4686 \\
\hline 13 & 64.7378 & 71.486 & 38 & 64.8162 & 71.5277 \\
\hline 14 & 64.8811 & 76.7877 & 39 & 64.9392 & 73.899 \\
\hline 15 & 67.149 & 71.6372 & 40 & 66.9181 & 73.6779 \\
\hline 16 & 66.9909 & 73.9153 & 41 & 64.9904 & 71.3731 \\
\hline 17 & 64.8782 & 71.5975 & 42 & 64.7865 & 71.5662 \\
\hline 18 & 64.8756 & 73.8302 & 43 & 64.6201 & 70.7853 \\
\hline 19 & 64.8773 & 71.6173 & 44 & 64.6883 & 71.4151 \\
\hline 20 & 66.9138 & 76.5577 & 45 & 64.5232 & 70.5279 \\
\hline 21 & 67.4006 & 72.4824 & 46 & 64.5299 & 71.1699 \\
\hline 22 & 64.9339 & 73.8115 & 47 & 64.308 & 69.802 \\
\hline 23 & 64.8771 & 71.6168 & 48 & 64.3463 & 70.7955 \\
\hline 24 & 64.878 & 71.62 & 49 & 63.9482 & 68.8861 \\
\hline
\end{tabular}

Table VII and VIII show the evaluation results obtained for the AODV in different scenarios used in this research. Table IX and $\mathrm{X}$ shows the evaluation results obtained for the AOMDV in different scenarios.

TABLE VII. ENERGY CONSUMPTION EVALUATION OF AODV

\begin{tabular}{|l|l|l|l|l|l|l|}
\hline $\mathbf{N}$ & PS & PR & PD & TE & ACE & ARE \\
\hline 10 & 396 & 396 & 0 & 539.368 & 53.9368 & 46.0632 \\
\hline 20 & 792 & 792 & 0 & 1171.87 & 58.5933 & 41.4067 \\
\hline 30 & 1188 & 1187 & 1 & 1822.18 & 60.7394 & 39.2606 \\
\hline 40 & 1584 & 1582 & 2 & 2710.98 & 67.7744 & 32.2256 \\
\hline 50 & 1980 & 1976 & 4 & 3268.67 & 65.3734 & 34.6266 \\
\hline
\end{tabular}

N: NO. OF NODES, PS: PACKET SENT, PR: PACKET RECEIVED, PD: PACKET DROPPED, TE: TOTAL ENERGY CONSUMED BY ALL NODES (JOULES), ACE: AVERAGE ENERGY CONSUMED BY EACH NODE,
TABLE VIII. PERFORMANCE EVALUATION OF AODV

\begin{tabular}{|l|l|l|l|l|l|l|}
\hline N & PDF \% & TR [bps] & TR kbps & E2ED (s) & RL & NRL \\
\hline 10 & 100 & 202752 & 16.42 & 0.017984 & 12 & 0.030 \\
\hline 20 & 100 & 405504 & 32.84 & 0.0322659 & 45 & 0.057 \\
\hline 30 & 99.9158 & 607744 & 49.21 & 0.0412604 & 159 & 0.134 \\
\hline 40 & 99.8737 & 809984 & 65.55 & 0.140721 & 527 & 0.333 \\
\hline 50 & 99.798 & 1011712 & 81.90 & 0.403008 & 664 & 0.336 \\
\hline \multicolumn{7}{|c|}{ N: NO. OF NODES, PDF: PACKET DELIVERY FRACTION, TR: THROUGHPUT RATE,E2ED: AVERAGE } \\
END-TO-END DELAY, RL: ROUTING LOAD, NRL: NORMALIZED ROUTING LOAD
\end{tabular}

TABLE IX. ENERGY CONSUMPTION EVALUATION OF AOMDV

\begin{tabular}{|l|l|l|l|l|l|l|}
\hline $\mathbf{N}$ & PS & PR & PD & TE & ACE & ARE \\
\hline 10 & 396 & 396 & 0 & 544.969 & 54.4969 & 45.503058 \\
\hline 20 & 792 & 792 & 0 & 1168.08 & 58.4041 & 41.595934 \\
\hline 30 & 1188 & 1188 & 0 & 1830.82 & 61.0275 & 38.972501 \\
\hline 40 & 1584 & 1583 & 1 & 2685.89 & 67.1473 & 32.852694 \\
\hline 50 & 1980 & 1977 & 3 & 3609.32 & 72.1863 & 27.813691 \\
\hline
\end{tabular}

N: NO. OF NODES, PS: PACKET SENT, PR: PACKET RECEIVED, PD: PACKET DROPPED, TE: TOTAL ENERGY CONSUMED BY ALL NODES (JOULES), ACE: AVERAGE ENERGY CONSUMED BY EACH NODE, ARE: AVERAGE RESIDUAL ENERGY FOR EACH NODE.

TABle X. Performance Evaluation of AOMdV

\begin{tabular}{|l|l|l|l|l|l|l|}
\hline $\mathbf{N}$ & PDF\% & TR $[$ bps $]$ & TR kbps & E2ED $(\mathbf{s})$ & RL & NRL \\
\hline 10 & 100 & 202752 & 16.42 & 0.01812 & 1005 & 2.538 \\
\hline 20 & 100 & 405504 & 32.84 & 0.02989 & 2027 & 2.559 \\
\hline 30 & 100 & 608256 & 49.25 & 0.03975 & 3110 & 2.618 \\
\hline 40 & 99.9369 & 810496 & 65.61 & 0.05884 & 4155 & 2.625 \\
\hline 50 & 99.8485 & 101222 & 81.92 & 0.07327 & 5219 & 2.64 \\
\hline
\end{tabular}

N: No. of Nodes, PDF: Packet Delivery Fraction, TR: Throughput Rate, E2ED: Average End-To-End Delay, RL: Routing Load, NRL: Normalized Routing Load

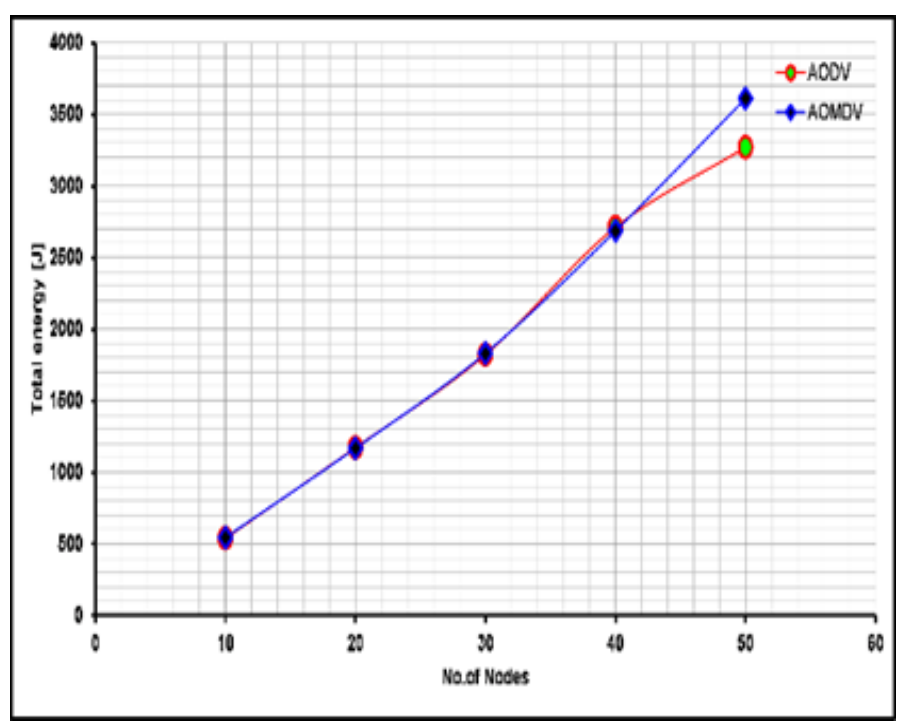

Fig. 8. Total Energy Consumed By All Nodes (Joules) Vs Number of Nodes. 


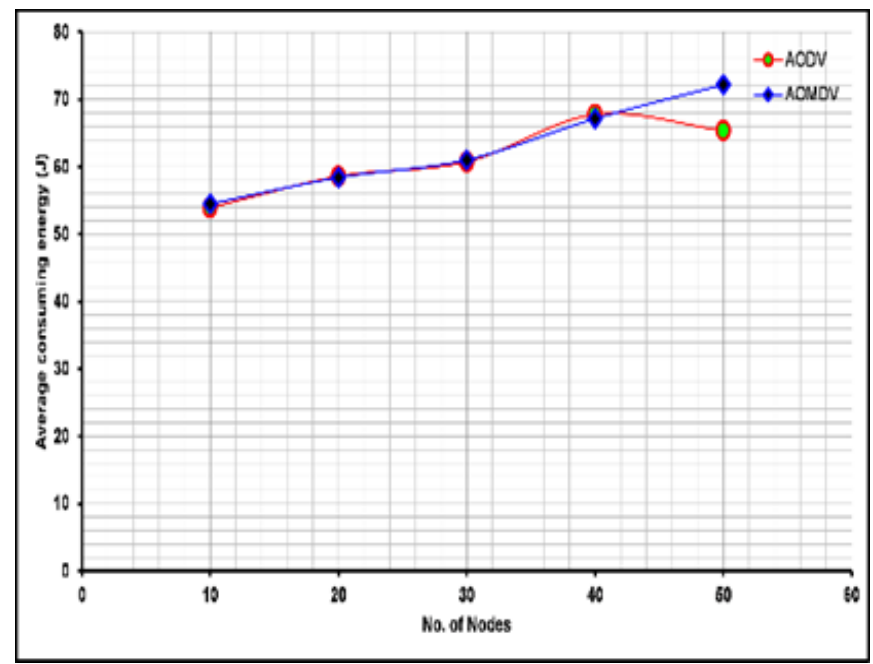

Fig. 9. Average Energy Consumed by each Nodes Vs Number of Node.

Fig. 8 shows the total energy consumed by all nodes of each scenario. The outcomes demonstrated that the AODV consumed less energy as compared to AOMDV, the possible reason behind this is that AODV is single-path protocol and found single path to destination due to which it consumed less energy. The term average energy consumed reflects the percentage of energy consumed by each node. Fig. 9 shows this result, which shows more energy consumed by the AOMDV when the number of nodes increased.

Fig. 10 shows the percentage of residual energy or battery life for each node in different scenarios, by using the equation number (4); it is clear from Fig. 10 that the AODV has more residual energy as compared to AOMDV. PDF indicates the percentage of packets that arrived at the destination successfully. Fig. 11 shows the PDF of AODV and AOMDV in the first two scenarios (at 10, 20 nodes with 1 and 2 connections) are almost same. However, with the increase in the number of nodes and CBR connections (at 30, 40, 50 nodes with $3,4,5$ connections) AOMDV showed better results as compared to AODV.

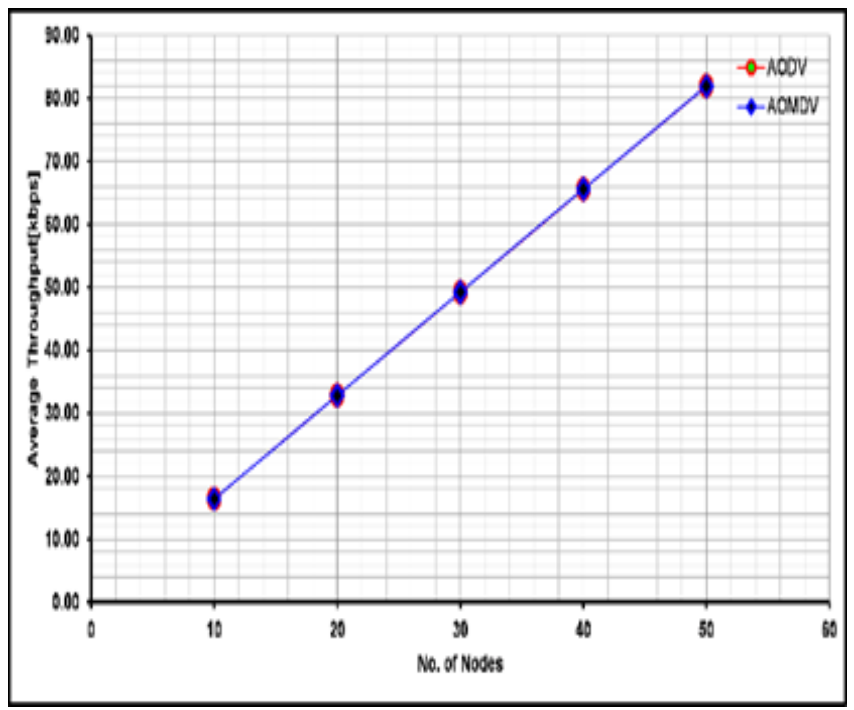

Fig. 10. Average Residual Energy Vs Number of Nodes.

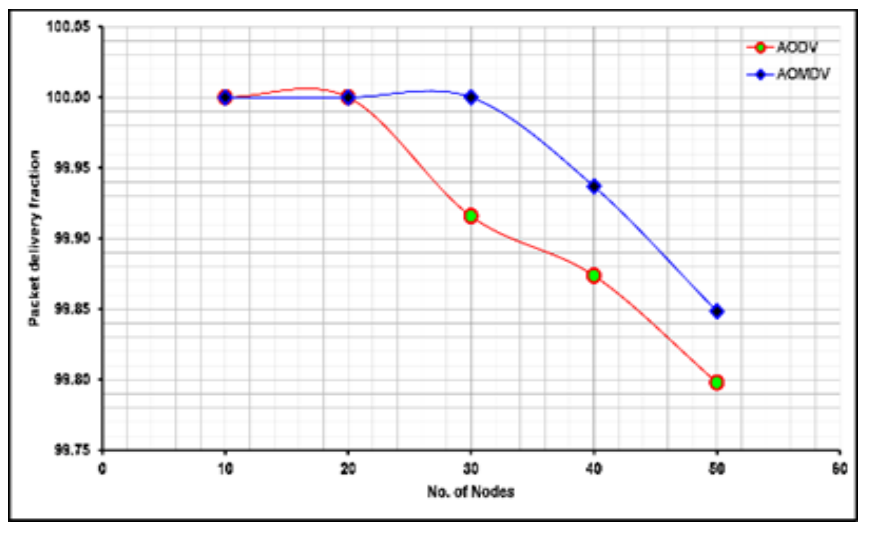

Fig. 11. Packet Delivery Fraction Vs Number of Nodes.

Fig. 12 shows the network throughput rate of AODV and AOMDV versus the number of nodes. Based on the results, AOMDV produced better throughput rate. In other words, when the number of nodes increased the AOMDV throughput increased and when the number of nodes decreased the AOMDV throughput decreased. AODV is a single-path routing protocol whose average end-to-end delay is higher as compared to multi-path protocols. Fig. 13 clearly shows the higher delay of AODV as the number of nodes and the number of connections increases, and in case of AOMDV it reduced. This is the nature of the AOMDV protocol, which works to find alternate paths when the basic path is lost without having to rediscover the path, and therefore does not require extra time.

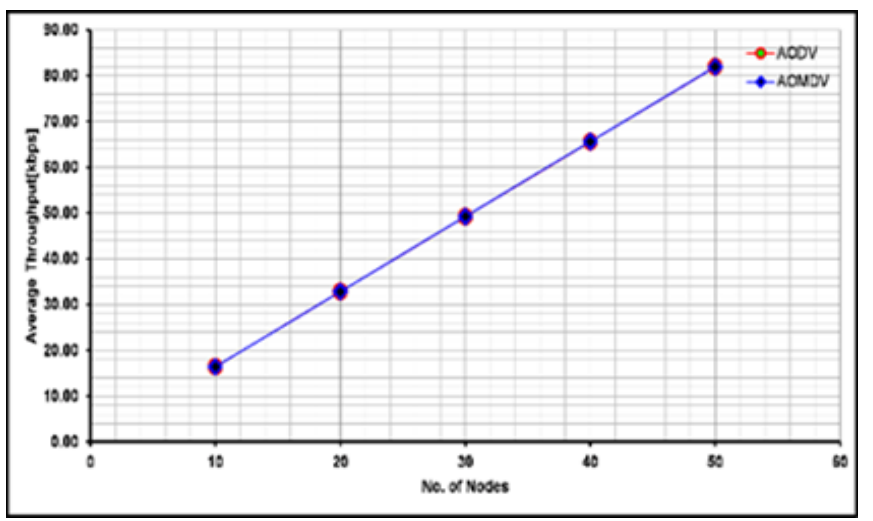

Fig. 12. Throughput Rate [kbps] Vs Number of Nodes.

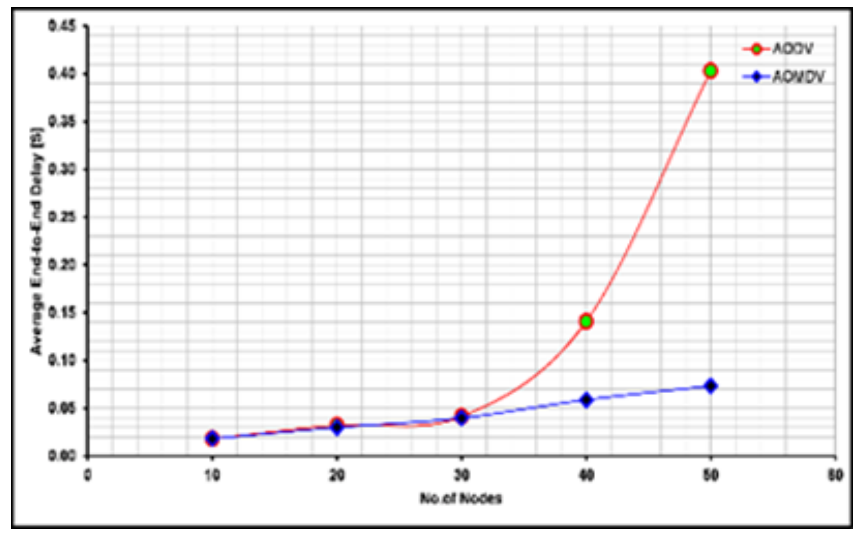

Fig. 13. Average End-to-End Delay Vs Number of Nodes. 


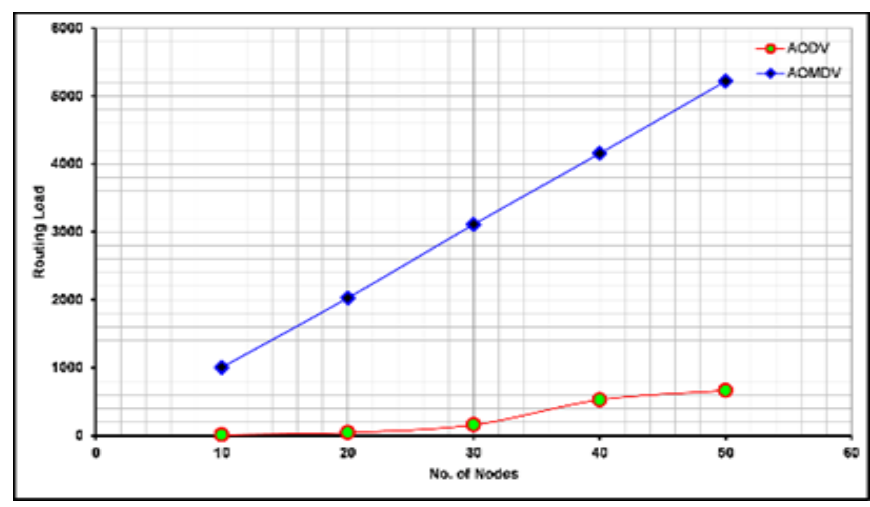

Fig. 14. Routing Load Vs Number of Nodes.

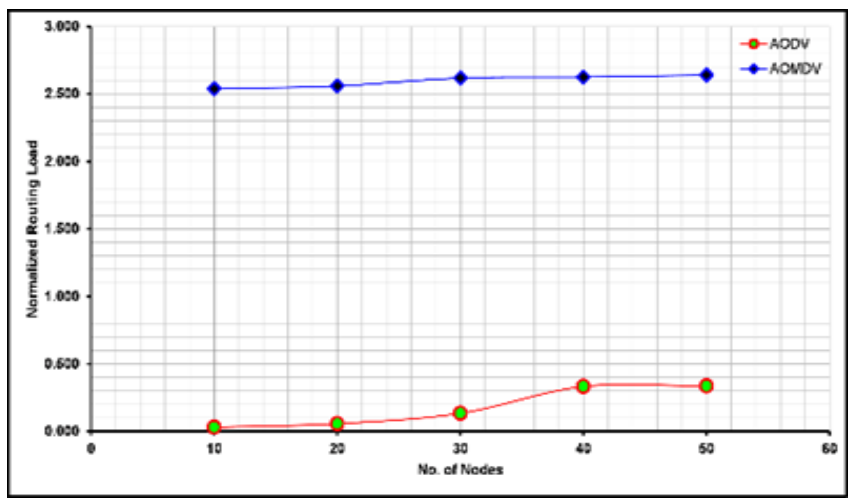

Fig. 15. Normalized Routing Load Vs Number of Nodes.

Routing load of AODV and AOMDV protocol is shown in Fig. 14. The simulation outcomes demonstrated that the AODV protocol produced less routing overhead because it is a singlepath protocol. NRL indicates the number of routing packets transmitted including the forwarded packets per data packets delivered at application layer to the destination. Fig. 15 shows the simulation results of the NRL of AODV and AOMDV at different number of nodes, and in various CBR connections. It has been observed that AOMDV has higher NRL. The reason is that routing overhead is higher in AOMDV because the nature of the protocol is multi-path, where the routing packets seeking to find many alternate routes are retained and are used in case of loss of connection of the main path in order to reduce end-to-end delay and increases packet delivery rate.

\section{CONCLUSION}

In this research performance evaluation of two routing protocols AODV and AOMDV in MANETs has been done. There is a lack of detailed evaluation of energy consumption of mobile ad-hoc network protocols. Furthermore, there is a great need to investigate the energy consumption of known-protocols in MANETs for future research studies. The vast majority of studies concentrated on performance parameters based on traditional performance metrics. This research provides a paradigm for future studies for the development of dynamic routing protocols, which are more efficient and effective in terms of energy consumption and producing less overhead.

Extensive simulation has been done in NS2 simulator, which includes ten scenarios, five for each protocol; vary in density of nodes and traffic. It has been concluded in this research that the performance of AOMDV is more optimal as compared to AODV in terms of packet delivery fraction, throughput and end-to-end delay. However, in terms of energy consumption and normalized routing load, AODV is more optimal as compared to AOMDV. It is also concluded that AOMDV is more suitable when the network is stable; however, its performance is reduced when the network topology changes frequently. Furthermore, there is a trade-off in AOMDV routing protocol between energy consumption on the one hand and PDF efficiency and throughout on the other hand.

\section{REFERENCES}

[1] E. Alotaibi and B. Mukherjee, "A survey on routing algorithms for wireless Ad-Hoc and mesh networks", Computer. Networks, vol. 56, no. 2, pp. 940-965, 2012. doi: 10.1016/j.comnet.2011.10.011.

[2] M. Zhang and P. H. J. Chong, "Performance Comparison of Flat and Cluster-Based Hierarchical Ad Hoc Routing with Entity and Group Mobility", in Proc. of IEEE Conf. on Wireless Communications and Networking, pp. 1-6, April 5,2009. doi: 10.1109/WCNC.2009.4917894.

[3] Y. Khamayseh, O. M. Darwish, and S. A. Wedian, "MA-AODV: Mobility Aware Routing Protocols for Mobile Ad Hoc Networks", in Proc. of 4th IEEE Conf. on Systems and Networks Communications, pp. 25-29, 2009. doi: 10.1109/ICSNC.2009.80.

[4] W. Wang and C. Amza, "Motion-based routing for opportunistic ad-hoc networks", in Proc. of 14th ACM Conf. on Modeling, analysis and simulation of wireless and mobile systems- MSWiM '11, pp. 169-178, October 31, 2011. doi: 10.1145/2068897.2068928.

[5] B. Malarkodi, P. Gopal, and B. Venkataramani, "Performance Evaluation of Adhoc Networks with Different Multicast Routing Protocols and Mobility Models", in Proc. of IEEE Conf. on Advances in Recent Technologies in Communication and Computing, pp. 81-84, October 27, 2009. doi: 10.1109/ARTCom.2009.29.

[6] A. Sarkar and T. Senthil Murugan, "Routing protocols for wireless sensor networks: What the literature says?", Alexandria Engineering Journal. Faculty of Engineering, vol. 55, no. 4, pp. 3173-3183, December, 2016. doi: 10.1016/j.aej.2016.08.003.

[7] S. M. Kamruzzaman and Md. Abdul Hamid, "An Energy Efficient Multichannel MAC Protocol for QoS Provisioning in MANETs," KSII Transactions on Internet and Information Systems, vol. 5, no. 4, pp. 684702, 2011. DOI: 10.3837/tiis.2011.04.004

[8] Anjali Anand, Rinkle Rani and Himanshu Aggarwal, "Energy Efficient and Secure Multipoint Relay Selection in Mobile Ad hoc Networks," KSII Transactions on Internet and Information Systems, vol. 10, no. 4, pp. 1571-1589, 2016. DOI: 10.3837/tiis.2016.04.006

[9] C. E. Perkins and E. M. Royer, "Ad-hoc on-demand distance vector routing", Proc. 2nd IEEE. Workshop on Mobile Computing Systems and Applications, pp. 90-100, 1999. doi: 10.1109/MCSA.1999.749281.

[10] C. Perkins, E. Belding-Royer, and S. Das, "Ad hoc on-demand distance vector (AODV) routing”, Internet Society, No. RFC 3561, pp. 1-37, 2003.

[11] M. K. Marina and S. R. Das, "On-demand multipath distance vector routing in ad hoc networks", in Proc. Of 9th IEEE Conf. on Network Protocols $(I C N P)$, Comput. Soc, pp. 14-23, November 11,2001. doi: 10.1109/ICNP.2001.992756.

[12] M. K. Marina and S. R. Das, "Ad hoc on-demand multipath distance vector routing", Wireless Communications and Mobile Computing, vol. 6, no. 7, pp. 969-988, November, 2006. doi: 10.1002/wcm.432.

[13] The Mendeley Support Team, Free reference manager and PDF organizer, Available at: http://www.mendeley.com/.

[14] M. Abolhasan, T. Wysocki, and E. Dutkiewicz, "A review of routing protocols for mobile ad hoc networks", Ad Hoc Networks, vol. 2, no. 1, pp. 1-22, 2004. doi: 10.1016/S1570-8705(03)00043-X.

[15] N. H. Saeed, M. F. Abbod, and H. S. Al-Raweshidy, "MANET routing protocols taxonomy", in Proc. of IEEE Conf. on Future Communication Networks, pp. 123-128, April 2, 2012. doi: 10.1109/ICFCN.2012.6206854. 
[16] B. J. Oommen and S. Misra, "A Fault-Tolerant Routing Algorithm for Mobile Ad Hoc Networks Using a Stochastic Learning-Based Weak Estimation Procedure", in Proc. of IEEE Conf. on Wireless and Mobile Computing, Networking and Communication (WiMob '2006), pp. 31-37, June 19, 2006. doi: 10.1109/WIMOB.2006.1696374.

[17] C.-C. Tseng and K.-C. Chen, "A Clustering Algorithm to Produce Power-Efficient Architecture for (N, B)-Connected Ad Hoc Networks", in Proc. of IEEE Conf. on Communications, pp. 3497-3502, June 24, 2007. doi: 10.1109/ICC.2007.578.

[18] H. Safa, O. Mirza, and H. Artail, "A Dynamic Energy Efficient Clustering Algorithm for MANETs", in Proc. of IEEE Conf. on Wireless and Mobile Computing, Networking and Communications, pp. 51-56, October 12, 2008. doi: 10.1109/WiMob.2008.67.

[19] S. Misra and G. Rajesh, "Bird Flight-Inspired Routing Protocol for Mobile Ad Hoc Networks", ACM Transactions on Autonomous and Adaptive Systems, vol. 6, no. 4:25, pp. 1-37, October, 2011. doi: 10.1145/2019591.2019594.

[20] S. Misra, P. V. Krishna, A. Bhiwal, A. S. Chawla, B. E. Wolfinger, and C. Lee, "A learning automata-based fault-tolerant routing algorithm for mobile ad hoc networks", The Journal of Supercomputing, , vol. 62, no. 1, pp. 4-23, October, 2012. doi: 10.1007/s11227-011-0639-8.

[21] A. Choukri, A. Habbani, and M. El Koutbi, "An energy efficient clustering algorithm for MANETs", in Proc. of IEEE Conf. on Multimedia Computing and Systems (ICMCS), pp. 819-824, 2014. doi: 10.1109/ICMCS.2014.6911232.

[22] J. John and R. Pushpalakshmi, "A reliable optimized clustering in MANET using Ant Colony algorithm", in Proc. of IEEE Conf. on Communication and Signal Processing, pp. 051-055, April 3,2014. doi: 10.1109/ICCSP.2014.6949797.

[23] S. B. Kulkarni and B. N. Yuvaraju, "Node connectivity, Energy and Bandwidth Aware Clustering Routing Algorithm for real-time traffic multicasting in MANET", in Proc. of IEEE Conf. on Advance Computing Conference (IACC), pp. 760-763, June 12, 2015. doi: 10.1109/IADCC.2015.7154809.

[24] R. Sahu and N. Chaudhari, "Energy Reduction Multipath Routing Protocol for MANET Using Recoil Technique", Electronics, vol. 7, no. 5, p. 56, April, 2018. doi: 10.3390/electronics7050056.

[25] S. Biradar and K. Majumder, "Performance Evaluation and Comparison of AODV and AOMDV", International Journal on Computer Science and Engineering, vol. 2, no. 2, pp. 373-377, 2010. Available at http://www.enggjournals.com/ijcse/doc/IJCSE10-02-02-47.pdf.

[26] J. Jacob and V. Seethalakshmi, "Performance analysis and enhancement of routing protocol in MANET", International Journal of Modern Engineering, vol. 2, no. 2 , pp. 323-328, Mach, 2012. Available at:
http://www.ijmer.com/papers/vol2_issue2/BA22323328.pdf.

[27] T. K. Araghi, M. Zamani, and A. B. A. Mnaf, "Performance Analysis in Reactive Routing Protocols in Wireless Mobile Ad Hoc Networks Using DSR, AODV and AOMDV", in Proc. of IEEE Conf. on Informatics and Creative Multimedia, pp. 81-84, 2013. doi: 10.1109/ICICM.2013.62.

[28] D. N. Patel, S. B. Patel, H. R. Kothadiya, P. D. Jethwa, and R. H. Jhaveri, "A survey of reactive routing protocols in MANET", in Proc. of IEEE Conf. on Information Communication and Embedded Systems (ICICES2014), pp. 1-6, February 27, 2014. doi: 10.1109/ICICES.2014.7033833.

[29] B. Paul, K. A. Bhuiyan, K. Fatema, and P. P. Das, "Analysis of AOMDV, AODV, DSR, and DSDV Routing Protocols for Wireless Sensor Network", in Proc. of IEEE Conf. on Computational Intelligence and Communication Networks (ICICES), pp. 364-369, November 14, 2014. doi: 10.1109/CICN.2014.88.

[30] B. Rekha and D. V. Ashoka, "Performance analysis of AODV and AOMDV routing protocols on scalability for MANETs", In Emerging Research in Electronics, Computer Science and Technology, pp. 173181. Springer, New Delhi, 2014. https://doi.org/10.1007/978-81-3221157-0_19.

[31] D. Lei, T. Wang, and J. Li, "Performance Analysis and Comparison of Routing Protocols in Mobile Ad Hoc Network", in Proc. of 5th IEEE Conf. on Instrumentation and Measurement, Computer, Communication and Control (IMCCC), pp. 1533-1536, September 18,2015. doi: 10.1109/IMCCC.2015.325.

[32] Network Simulator NS2 and Network Animator NAM, Available at: http://www.isi.edu/nsnam (Accessed 12 Juley 2017)

[33] T. Issariyakul and E. Hossain, Introduction to Network Simulator NS2, Springer Science and Business Media, 2nd Edition, Springer, New York, 2011. doi: 10.1007/978-0-387-71760-9.

[34] K. Fall and K. Varadhan, The ns Manual (formerly ns Notes and Documentation). The VINT project, 47,2005 . Available at: http://www.isi.edu/nsnam/ns/ns-documentation.html.

[35] J. Yoon, M. Liu, and B. Noble, "Random waypoint considered harmful", in IEEE INFOCOM 2003, Twenty-second Annual Joint Conference of the IEEE Computer and Communications Societies (IEEE Cat. No.03CH37428), vol. 2, pp. 1312-1321, March 30, 2003. doi: 10.1109/INFCOM.2003.1208967.

[36] D.B. Close, A.D. Robbins, P.H. Rubin and R. Stallman, The GAWK manual, 0.15 Edition, Free Softare Fwoundation, Inc, Cambridge, MA, April, 1993.

[37] A. D. Robbins, AWK language programming. 1.0 Edition, Free Software Foundation, Inc, Boston, UAS, 1996. 